\title{
Baton twirling: another cause of eye injury
}

\author{
AI FERN,' P KYLE,' AND D ALLAN² \\ From the 'Southern General Hospital, Glasgow, and the 'West of Scotland Health Board's Department of \\ Clinical Physics and Bioengineering, Glasgow
}

SUMMARY Baton twirling is an increasingly popular sport, with an estimated 5000 participants in Scotland alone. The baton, weighing over $200 \mathrm{~g}$, is spun at high speeds and frequently thrown over 40 feet $(12 \mathrm{~m})$ into the air. We report a case of a 17-year-old girl who sustained a serious eye injury after being struck by a baton. The occurrence of eye injury has not been reported in this sport, and we discuss the potential for injury.

It is well recognised that sport accounts for a considerable percentage of eye injuries, particularly racket and contact sports. ${ }^{12}$ Baton twirling is a minority sport but its popularity is growing rapidly, and the potential for eye injury is high. Eye injury has not previously been reported, but this case illustrates the potential danger of the sport.

\section{Case report}

A 17-year-old girl was admitted having been struck in the left eye by one end of her falling baton. At the time of admission she had a tense orbital haematoma with periorbital bruising, proptosis, and marked chemosis. Traumatic mydriasis was present though no intraocular haemorrhage. $X$-rays showed a blowout fracture of her left orbital floor. Her initial visual acuity was $6 / 60$ due to a combination of optic nerve compression by the orbital haematoma and macular oedema. Her visual acuity was tested half hourly, and by the following morning vision had improved to $6 / 24$, so that there was no need for orbital decompression. Subsequently vision improved to $6 / 18$ after seven days and eventually to $6 / 6$ at eight weeks.

Her eye movements were limited in all directions of gaze at the outset, a product of the orbital haematoma. As the haematoma resolved, eye movements improved, leaving only the limitation of elevation produced by the fracture. This settled, satisfactorily spontaneously, and eight weeks after the accident eye movements were full and diplopia could not be elicited.

Correspondence to Dr AI Fern, Southern General Hospital, Glasgow G51 4TF.

\section{Discussion}

The sport of baton twirling is comparable to gymnastics and has shared that sports' recent growth in popularity. The participants tend to be girls of teenage and primary school age. The sport is governed by its National Federation, which organises tournaments with graded competition, and at the highest level international events are held. At present in Scotland there are 2000 registered competitors with an estimated further 8000 nonregistered participants. To put it in context this overall figure of 10000 can be compared to more popular sports: 80000 people play squash in Scotland; 120000 play tennis. ${ }^{3}$ Whereas the figures for squash and tennis are static, those for baton twirling have more than doubled in the last five years.

The sport involves spinning a baton about the head and body as well as throwing it into the air and catching it. On occasions the baton can be thrown as high as $15 \mathrm{~m}$. The standard baton is $64 \mathrm{~cm}$ long, made of tubular steel with two hard rubber end-stops weighing $20 \mathrm{~g}$ and $30 \mathrm{~g}$ respectively, and an overall weight of $214 \mathrm{~g}$. The diameters of the end-stops are $3 \mathrm{~cm}$ and $4 \mathrm{~cm}$ respectively, and both are capable of entering the orbit.

Table 1 Rotational force of baton

$$
\begin{aligned}
& \text { Spinning at } 5 \mathrm{rev} / \mathrm{s} \\
& \begin{aligned}
\text { Kinetic energy } & =1 / 2 \mathbf{I} \mathbf{w}^{2} \\
& =1 / 2 \mathbf{I}(2 \pi \mathrm{f})^{2}
\end{aligned}
\end{aligned}
$$

Assuming displacement of eye of $1 \mathrm{~cm}$ :

Force of impact $=530 \mathrm{~N}$ 
Table 2 Gravitational force of baton

$$
\begin{aligned}
& \text { Falling from } 15 \mathrm{~m} \\
& \begin{aligned}
\text { Kinetic energy } & =\mathrm{mgh} \\
& =0.214 \mathrm{~kg} \times 9.8 \mathrm{~ms}^{-1} \times 15 \mathrm{~m}
\end{aligned}
\end{aligned}
$$

Force of impact $=3150 \mathrm{~N}$

Force of rotation $=3150+530$

$$
\text { and gravity } \quad=3680 \mathrm{~N}
$$

Table 3 Force of a squash ball

$$
\begin{aligned}
& \text { Assuming ball travelling at } 120 \mathrm{mph} \\
& \text { weighing } 25 \mathrm{~g} \text { : } \\
& \begin{aligned}
120 \mathrm{mph} & =54 \mathrm{~ms}^{-1} \\
\mathrm{KE} \quad & =1 / 2 \mathrm{M} \mathrm{V}^{2} \\
& =1 / 2 \times 0.025 \mathrm{~kg} \times\left(54 \mathrm{~ms}^{-1}\right)^{2} \\
& =36.45 \mathrm{~J}
\end{aligned}
\end{aligned}
$$

Assuming displacement of eye of $1 \mathrm{~cm}$ :

Force of impact $=3645 \mathrm{~N}$

The baton cannot be spun faster than 5 revolutions/ second and at this rate the force generated by the end of the baton is $530 \mathrm{~N}$ (Table 1). Similarly a baton falling from $15 \mathrm{~m}$ has a force of impact of $3150 \mathrm{~N}$ (Table 2). Thus the maximum force of a baton spinning at 5 revolutions/second and falling from $15 \mathrm{~m}$ is $3680 \mathrm{~N}$.

It is estimated that a squash ball travels at speeds of up to $120 \mathrm{mph}\left(54 \mathrm{~ms}^{-1}\right){ }^{4}$ At this speed a squash ball weighing $25 \mathrm{~g}$ has a force of impact of $3645 \mathrm{~N}$ (Table
$3)$, similar to the force of the baton. Both the endstops of the baton and the squash ball can enter the orbit, but they are not directly comparable. The hard rubber of the end-stop transmits most of its force of impact to deforming the eye, while a large amount of the force of the squash ball is absorbed deforming the ball itself.

Thus baton twirling, a sport growing in popularity, has the potential to cause serious eye injury, especially in young people. The forces involved are similar to those in squash ball injuries, the dangers of which have been well documented.5 Eye protection, although recommended, is unlikely to be widely adopted. It is therefore important to be aware of the potential dangers of eye injury in this expanding sport. Interestingly, since this case the governing body of the sport has insisted on all competitors being insured against injury, particularly eye injury.

\section{References}

1 Vinger PF. Sports eye injuries: a preventable disease. Ophthalmology 1981; 88: 108-12.

2 Burke AJ, Sanitato JJ, Vinger PF, Raymond LA, Kulwin DR. Soccerball induced eye injuries. JAMA 1983; 249: 2682-5.

3 Officer of Population Censuses and Surveys. Series GHS No. 13. General Household Survey 1983. London: HMSO, 1985.

4 Scrivener AB. Impact resistant lenses. Br J Physiol Opt 1973; 28: 26-33.

5 Barrell GV, Cooper PJ, Eckington AR, MacFadyen JM, Powell RG, Tormey P. Squash ball to eyeball: the likelihood of squash players incurring an eye injury. Br Med J 1981; 283: 893-5.

Accepted for publication 20 November 1986. 